\title{
Indoleamine 2,3-dioxygenase 1 and overall survival of patients diagnosed with esophageal cancer
}

\author{
Ari J. Rosenberg ${ }^{4,9}$, Derek A. Wainwright ${ }^{1,2}$, Alfred Rademaker ${ }^{1,3}$, Carlos Galvez $^{4}$, \\ Matthew Genet ${ }^{4}$, Lijie Zhai ${ }^{2}$, Kristen L. Lauing ${ }^{2}$, Mary F. Mulcahy ${ }^{1,4,9,10}$, John P. \\ Hayes $^{1,5}$, David D. Odell ${ }^{1,6}$, Craig Horbinski ${ }^{1,7}$, Srinadh Komanduri ${ }^{8}$, Marie-Pier \\ Tetreault $^{8}$, Kwang-Youn A. Kim ${ }^{3}$ and Victoria M. Villaflor ${ }^{1,4,9,10}$ \\ ${ }^{1}$ Robert H. Lurie Comprehensive Cancer Center, Northwestern University, Chicago, 60611 IL, USA \\ ${ }^{2}$ Department of Neurological Surgery, Feinberg School of Medicine of Northwestern University, Chicago, 60611 IL, USA \\ ${ }^{3}$ Department of Preventive Medicine, Feinberg School of Medicine of Northwestern University, Chicago, 60611 IL, USA \\ ${ }^{4}$ Department of Medicine, Feinberg School of Medicine of Northwestern University, Chicago, 60611 IL, USA \\ ${ }^{5}$ Department of Radiation Oncology, Northwestern University, Chicago, $60611 \mathrm{IL}$, USA \\ ${ }^{6}$ Department of Thoracic Surgery, Northwestern University, Chicago, $60611 \mathrm{IL}$, USA \\ ${ }^{7}$ Department of Pathology, Northwestern University, Chicago, 60611 IL, USA \\ ${ }^{8}$ Department of Gastroenterology, Northwestern University, Chicago, $60611 \mathrm{IL}$, USA \\ ${ }^{9}$ Division of Hematology and Oncology, Northwestern University, Chicago, 60611 IL, USA \\ ${ }^{10}$ Northwestern Medicine Developmental Therapeutics Institute, Chicago, $60611 \mathrm{IL}$, USA \\ Correspondence to: Victoria M. Villaflor, email: Victoria.villaflor@nm.org
}

Keywords: esophageal cancer; indoleamine 2,3 dioxygenase; immunotherapy; checkpoint inhibitor; the cancer genome atlas Received: December 23, $2017 \quad$ Accepted: April 04, $2018 \quad$ Published: May 04, 2018

Copyright: Rosenberg et al. This is an open-access article distributed under the terms of the Creative Commons Attribution License 3.0 (CC BY 3.0), which permits unrestricted use, distribution, and reproduction in any medium, provided the original author and source are credited.

\section{ABSTRACT}

Background: Indoleamine 2,3-dioxygenase 1 (IDO1) is an enzyme with immunomodulatory properties that has emerged as a potential immunotherapeutic target in human cancer. However, the role, expression pattern, and relevance of IDO1 in esophageal cancer (EC) are poorly understood. Here, we utilize gene expression analysis of the cancer genome atlas (TCGA) and immunohistochemistry (IHC) to better understand the role and prognostic significance of IDO1 in EC.

Results: High IDO1 mRNA levels were associated with worse overall survival (OS) in both esophageal squamous cell carcinoma $(\mathrm{SCC})(P=0.02)$ and adenocarcinoma (AC) $(P=0.036)$. High co-expression of IDO1 and programmed death ligand 1 (PD-L1) was associated with worse OS in SCC $(P=0.0031)$ and AC $(P=0.0186)$. IHC for IDO1 in SCC showed a significant correlation with PD-L1 $(P<0.0001)$ and CD3 $\varepsilon(P<0.0001)$.

Conclusions: EC with high IDO1 and PD-L1 expression is significantly correlated with decreased patient survival, and may correlate with increased T-cells. These data suggest that simultaneous inhibition of IDO1 and PD-(L)1 may overcome important barriers to T-cell mediated immune rejection of EC.

Materials and Methods: mRNA expression data from TCGA (SCC $N=87 ; A C N=97)$. IHC in a second cohort of EC $(N=93)$ were stained for IDO1, PD-L1, and CD3 $\varepsilon$, followed by light microscopic analysis. 


\section{INTRODUCTION}

Esophageal cancer is a major cause of morbidity and mortality in the United States and worldwide. In 2017, an estimated 16,940 new cases and 15,690 deaths are expected due to esophageal cancer in the United States [1]. While the incidence of squamous cell carcinoma (SCC) of the esophagus is declining, esophageal adenocarcinoma (AC) and tumors of the gastroesophageal junction (GEJ) are increasingly common [1]. Despite advances in the treatment of esophageal and GEJ cancer, overall 5-year survival remains dismal [2]. Treatment for locally advanced disease typically includes a combination of chemotherapy and radiation, followed by surgical resection. Treatment for metastatic disease consists of palliative chemotherapy alone [2]. Targeted therapies have been extensively explored in esophageal and GEJ cancers, but with very limited success [3-8]. Trastuzumab, a monoclonal antibody that targets epidermal growth factor receptor 2 (Her2), is an option for the minority of patients with esophageal AC and GEJ tumors that overexpress Her2 [6]. Ramicurumab is a monoclonal antibody that targets vascular endothelial growth factor receptor (VEGFR) and offers a marginal benefit $[7,8]$. Despite these small steps towards improved systemic therapy options in advanced esophageal and GEJ cancer, there is critical clinical need to improve therapeutic efficacy.

The recent success of immune checkpoint blockade in enhancing survival for a variety of cancers including melanoma, non-small cell lung and renal cell has sparked interest in its potential application for esophageal tumors. Immunotherapies that boost $\mathrm{T}$ cell efficacy aimed at the destruction of cancer cells have generated excitement for utilizing the release of endogenous immune response to control malignant progression. In particular, the inhibition of PD-1 and cytotoxic T lymphocyte antigen-4 (CTLA-4), has demonstrated clinical benefit in a number of malignancies [9] such as melanoma [10, 11], lung cancer [12], bladder cancer [13], kidney cancer [14], head and neck cancer [15], hepatocellular carcinoma [16], merkel cell carcinoma [17], Hodgkin lymphoma [18], gastric cancer [19], and microsatellite instability - high (MSI-high) tumors [20]. Combination checkpoint inhibition of PD-1 with CTLA-4 has been evaluated in melanoma, leading to a higher rate of objective response, progression free survival (PFS) and marginally overall survival (OS) than with anti-PD-1 alone, albeit with greater levels of toxicity [21, 22]. In advanced gastroesophageal cancer, response rates to single-agent checkpoint inhibitors in patient populations unselected for PD-L1 range from $11 \%-17 \%$, while the response rate in patients selected for $\mathrm{PD}-\mathrm{L1}^{+}$tumors range from $13 \%-30 \%$ [19, 23-26]. In combination with CTLA-4 inhibition, response rates as high as $26 \%$ in unselected and $44 \%$ for PD-L1 ${ }^{+}$tumors have been observed [23]. Although these results with checkpoint inhibitors are exciting and encouraging leading to FDA approval, strategies to improve overall response rates, duration of response, and OS are needed.
A number of immunosuppressive factors associated with immune tolerance within the tumor microenvironment are being investigated as potential therapeutic targets to further amplify the antitumor activity mediated by checkpoint inhibition. One of these factors, indoleamine 2,3-dioxygenase 1 (IDO1), is overexpressed in a number of human malignancies in both tumor and stromal tissue, and is a major contributor to cancer-induced immune evasion [27]. IDO1 mediates the catalysis rate-limiting step in tryptophan degradation converting tryptophan into kynurenine [28], and demonstrates negative immunomodulatory properties [29]. IDO1 suppresses T-cell activity mediated by downstream stress response such as general control non-depressible 2 (GCN2) pathway and mTOR [29]. Depletion of tryptophan by IDO1 induces T-cell apoptosis and dysfunction [30], while accumulation of kynurenines are thought to induce immunosuppressive regulatory T-cells (Tregs). Further work has demonstrated that IDO1 expression is associated with inflammation within tumors [31]. IDO1 is induced by the pro-inflammatory cytokine, IFN $\gamma$, which also enhances expression of other key regulatory molecules including PD-L1 [32]. Patients treated with checkpoint inhibitors, such as PD-1 blockade, tend to have more robust clinical response in the setting of increased pre-treatment tumorinfiltrating lymphocytes [33]. Collectively, these findings support the hypothesis that the inhibition of IDO1 may increase intratumoral inflammation and increase tumor susceptibility to checkpoint inhibition, making it an ideal target for combining with the inhibition of PD-1 and/or CTLA-4. To the best of our knowledge, IDO1 expression in esophageal and GEJ tumors has not been extensively investigated. In this manuscript, we investigate the role, expression pattern, and relevance of IDO1 in esophageal cancer via gene expression analysis of the cancer genome atlas (TCGA) and quantitative immunohistochemistry (IHC) of surgically resected esophageal tumors.

\section{RESULTS}

\section{IDO1 expression is associated with worse patient survival in esophageal cancer}

Checkpoint marker expression in esophageal cancer was explored and expression was correlated with patient survival. Using mRNA expression data from TCGA for esophageal SCC and AC, expression of IDO1, PD1, PD-L1, CTLA-4, Her2, and OX-40 was evaluated (Figures 1A-1F; 2A-2F). Expression levels by mRNA were quantified and correlated with OS. Patient samples were separated into SCC and AC based on histology for survival analysis. Cutoff Finder was utilized to generate individual cutoff values of each marker to define high and low mRNA expression. Patient survival was estimated using Kaplan-Meier analysis. The SCC cohort evaluated 
included a sample size of 87 patients, while the AC cohort assessed 97 patient samples.

High IDO1 mRNA levels were significantly correlated with decreased patient survival for both esophageal SCC and AC. In the SCC cohort, median OS for high versus low IDO1 mRNA levels were 15.9 months and 41.5 months respectively (Figure 1A; $P=$ 0.02). Similarly, in the esophageal AC cohort, median OS was 20.1 months and 58.6 months in high and low IDO1 mRNA levels respectively (Figure $2 \mathrm{~A} ; P=0.036$ ).

The prognostic significance of other immune checkpoints in these patient samples were also assessed. There was a significantly shorter patient survival in patients with high PD-L1 mRNA levels when compared with low PD-L1 expression in both the esophageal SCC and AC cohorts. In the SCC cohort, the overall survival for high versus low PD-L1 expression was 15.9 months compared with 28.1 months, respectively (Figure 1C; $P=0.0032)$. In the esophageal AC patient cohort, median OS was 22.8 months for high PD-L1 mRNA levels while median OS was not reached (NR) for low PD-L1 (Figure 2C; $P=0.025$ ). Interestingly, there was a statistically significant difference in OS when stratified by PD-1 expression for esophageal AC, with median OS for high and low PD-1 mRNA levels of 20.1 months and 58.6 months, respectively (Figure $2 \mathrm{~B} ; P=0.023$ ). Other relevant markers in esophageal cancer samples including CTLA-4, Her2, and OX40 were also evaluated for correlation with survival (Figures 1D-2F; Figures 2D-2F), however, differences in patient survival did not reach statistical significance with the exception of Her2 in AC (Figure 2E; $P=0.0076$ )

\section{IDO1 and PD-(L)1 co-expression is associated with decreased survival in esophageal cancer}

Checkpoint marker co-expression of IDO1 with PD-1, PD-L1, CTLA-4, Her2, and OX-40 was also evaluated. (Figures 3A-3F; 4A-4F). Co-expression of mRNA for IDO1 and PD-L1 was found to be correlated with patient survival in esophageal cancer. SCC patients with high IDO1 and PD-L1 co-expression compared with low IDO1 and PD-L1 co-expression possessed a median $O S$ of 13.7 months and 41.5 months, respectively (Figure $3 \mathrm{C} ; P=0.0031$ ). A similar analysis for patients with AC samples was performed. Patient samples with high IDO1 and PD-L1 levels correlated with a median overall survival of 20.2 months compared to 58.6 months in patients with low IDO1 and PD-L1 expression (Figure 4C; $P=0.0186$ ).

When comparing survival in patients with coexpression of IDO1 and PD-1, similar findings for both SCC and AC histologies were identified. In SCC, patients with high IDO1 and PD-1 expression compared with low expression for these markers, median overall survival was 15.1 months and 41.5 months, respectively. (Figure 3B; $P=0.0151)$ Similarly, in AC, patients that demonstrated high versus low IDO1 and PD-1 co-expression had a median overall survival of 15.8 months and 58.6 months, respectively (Figure 4B; $P=0.0148$ ).
A

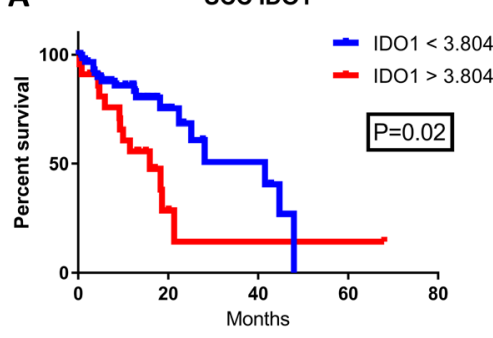

D

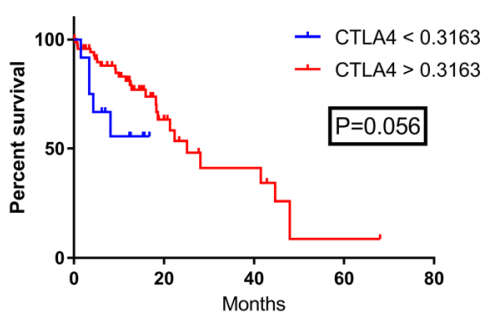

B

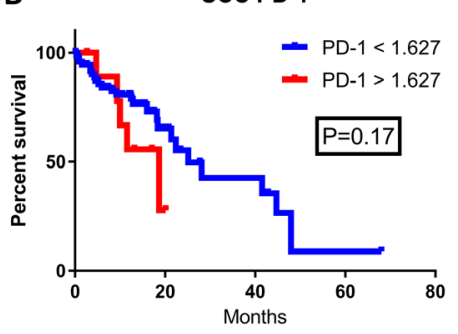

E

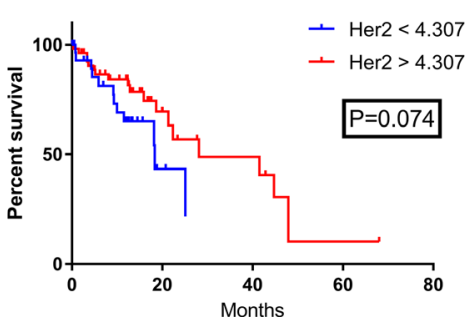

SCC PD-L1

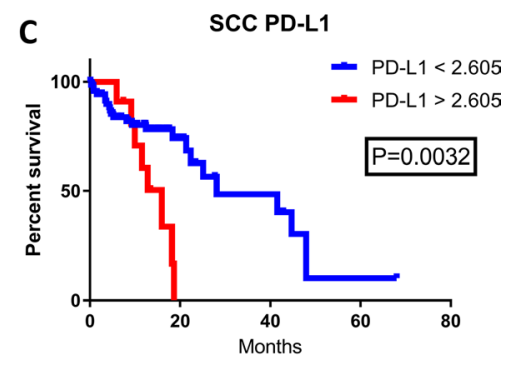

$\mathbf{F}$

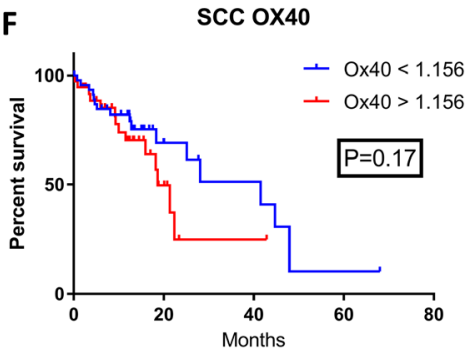

Figure 1: The correlation of patient survival with immune checkpoint expression mRNA levels in esophageal squamous cell carcinoma. TCGA mRNA expression data was collected on 87 patients with SCC, and a Cutoff Finder software was used to define high and low levels of each marker. High (red) and low (blue) expression was correlated with OS using the Kaplan-Meier survival analysis of (A) IDO1; high $n=24$, low $n=63$, (B) PD-1; high $n=12$, low $n=75$, (C) PD-L1; high $n=12$, low $n=75$, (D) CTLA4; high $n=75$, low $n=12$, (E) Her2; high $n=56$, low $n=31$, and (F) OX40; high $n=40$, low $n=47$. 


\section{IDO1 has a high rate of co-expression with other checkpoint markers in esophageal cancer}

To understand the correlation of IDO1 with other immunosuppressive factors in esophageal cancer, the expression levels of other genes in available esophageal cancer patient samples were stratified into IDO1-low and IDO1-high groups (Figures 3A, 4A). This comparison suggests that overexpression of PD-1, PD-L1, and CTLA-4, may be associated more frequently with high IDO1 mRNA levels compared with low IDO1 mRNA levels.
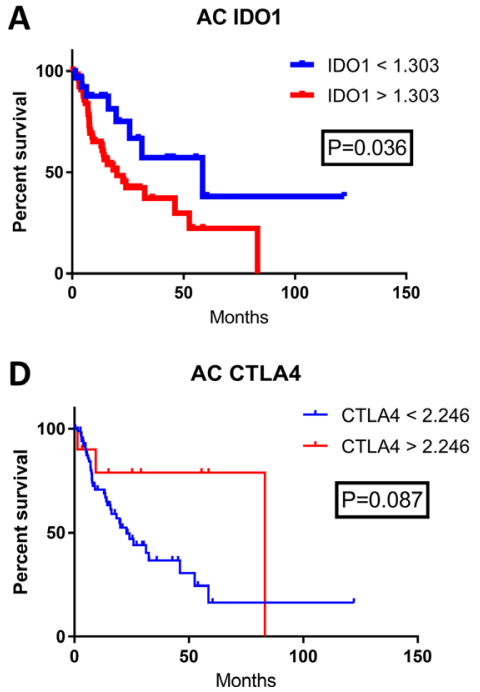
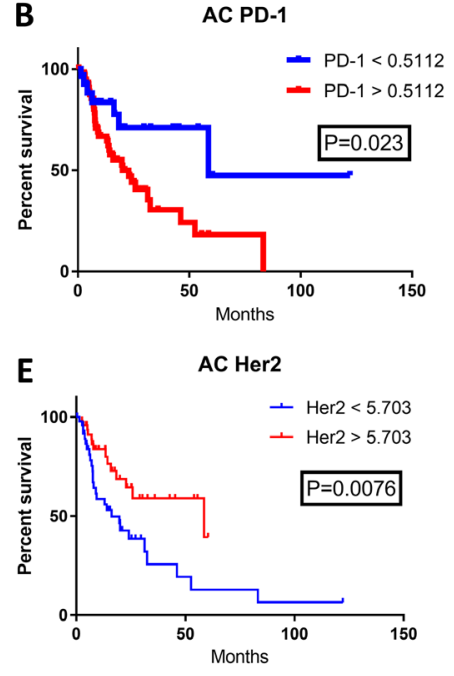

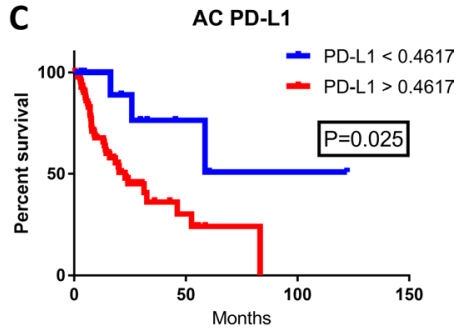

$\mathbf{F}$

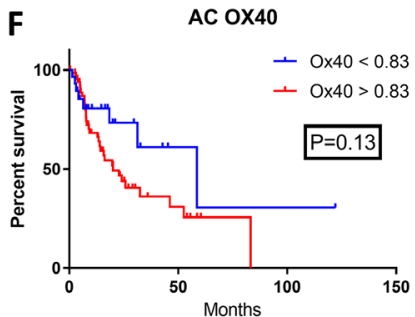

Figure 2: The correlation of patient survival with immune checkpoint expression mRNA levels in esophageal adenocarcinoma. TCGA mRNA expression data was collected on 97 patients with esophageal adenocarcinoma, and a Cutoff Finder software was used to define high and low levels of each marker. High (red) and low (blue) expression was correlated with OS using the Kaplan-Meier survival analysis of (A) IDO1; high $n=68$, low $n=29$, (B) PD-1; high $n=69$, low $n=28$, (C) PD-L1; high $n=86$, low $n=11$, (D) CTLA4; high $n=10$, low $n=87$, (E) Her2; high $n=49$, low $n=48$, and (F) OX40; high $n=68$, low $n=29$.

A

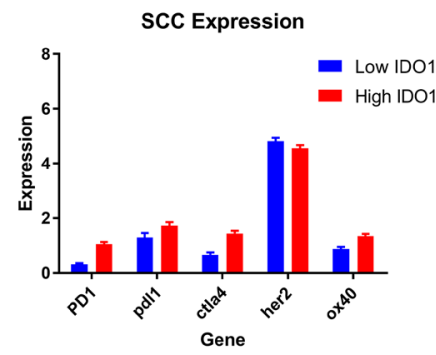

D SCC CTLA4 and IDO1

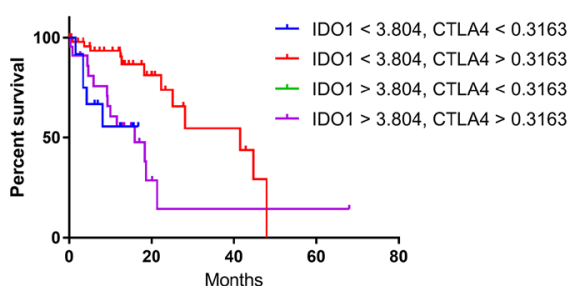

B

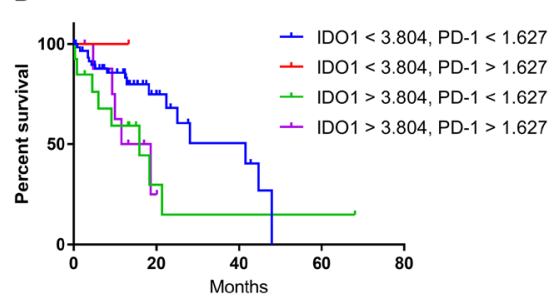

E

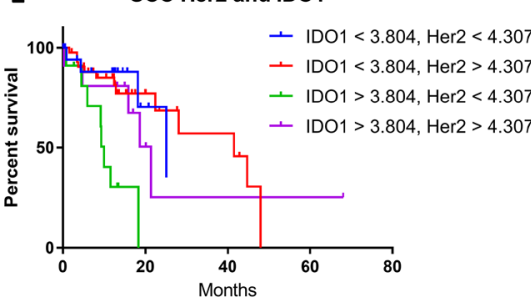

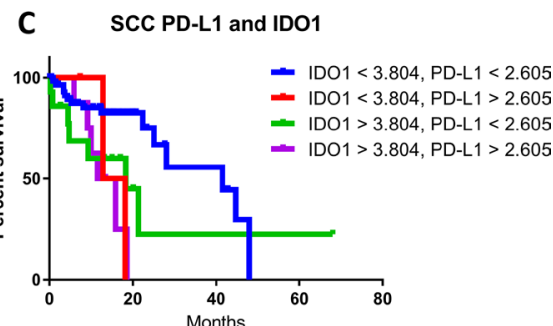

F $\quad \operatorname{Scc} 0 \times 40$ and IDO1

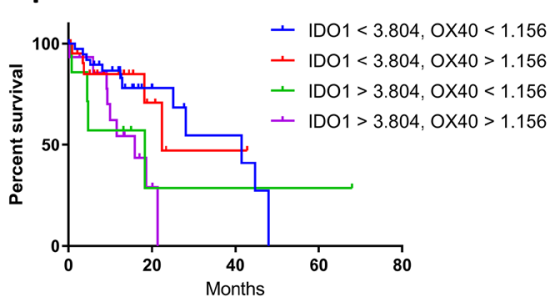

Figure 3: (A) High (red) and low (blue) IDO1 expression in patient samples stratified by gene co-expressors in SCC. The correlation of patient survival with variable IDO1 co-expression in SCC with (B) PD-1, (C) PD-L1, (D) CTLA-4, (E) Her2, and (F) OX-40. TCGA mRNA expression data was collected on 87 patients with esophageal SCC, and a Cutoff Finder software was used to define high and low levels of each marker in addition to IDO1. Co-expression groups for each marker were stratified in four groups: (B) High PD-1 and high IDO1, high PD-1 and low IDO1, low PD-1 and high IDO1, and low PD-1 and low IDO1. (C) High PD-L1 and high IDO1, high PD-L1 and low IDO1, low PD-L1 and high IDO1, and low PD-L1 and low IDO1. (D) High CTLA4 and high IDO1, high CTLA4 and low IDO1, low CTLA4 and high IDO1, and low CTLA4 and low IDO1. (E) High Her2 and high IDO1, high Her2 and low IDO1, low Her2 and high IDO1, and low Her2 and low IDO1. (F) High OX40 and high IDO1, high OX40 and low IDO1, low OX40 and high IDO1, and low OX40 and low IDO1. Kaplan-meier survival curves were plotted for each cohort respectively. 
A

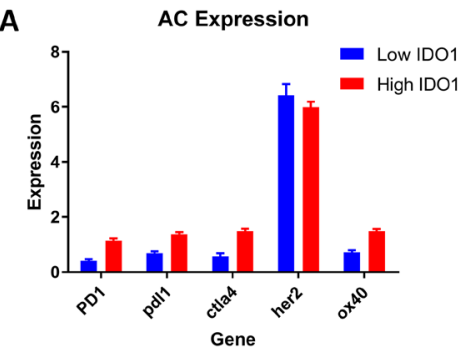

D

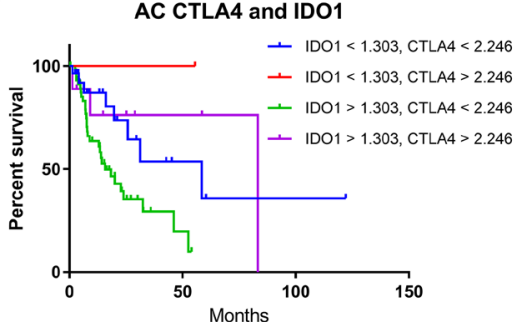

B

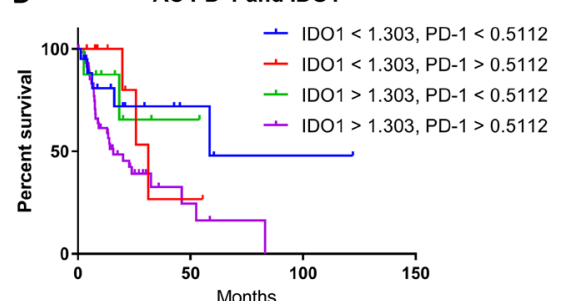

E

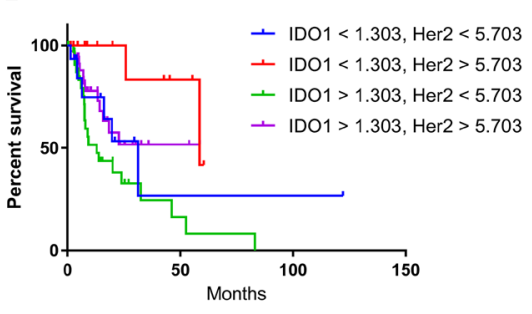

C

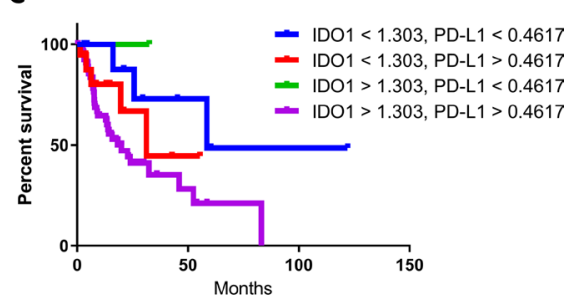

$\mathbf{F}$

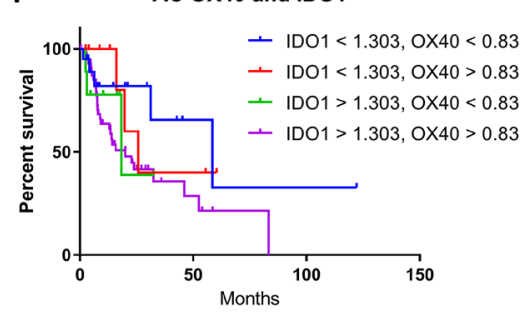

Figure 4: (A) High (red) and low (blue) IDO1 expression in patient samples stratified by genes in AC. The correlation of patient survival with variable IDO1 co-expression in AC with (B) PD-1, (C) PD-L1, (D) CTLA-4, (E) Her2, and (F) OX-40. TCGA mRNA expression data was collected on 97 patients with esophageal adenocarcinoma, and a Cutoff Finder software was used to define high and low levels of each marker in addition to IDO1. Co-expression groups for each marker were stratified in four groups: (B) High PD-1 and high IDO1, high PD-1 and low IDO1, low PD-1 and high IDO1, and low PD-1 and low IDO1. (C) High PD-L1 and high IDO1, high PD-L1 and low IDO1, low PD-L1 and high IDO1, and low PD-L1 and low IDO1. (D) High CTLA4 and high IDO1, high CTLA4 and low IDO1, low CTLA4 and high IDO1, and low CTLA4 and low IDO1. (E) High Her2 and high IDO1, high Her2 and low IDO1, low Her2 and high IDO1, and low Her2 and low IDO1. (F) High OX40 and high IDO1, high OX40 and low IDO1, low OX40 and high IDO1, and low OX40 and low IDO1. Kaplan-meier survival curves were plotted for each cohort respectively.

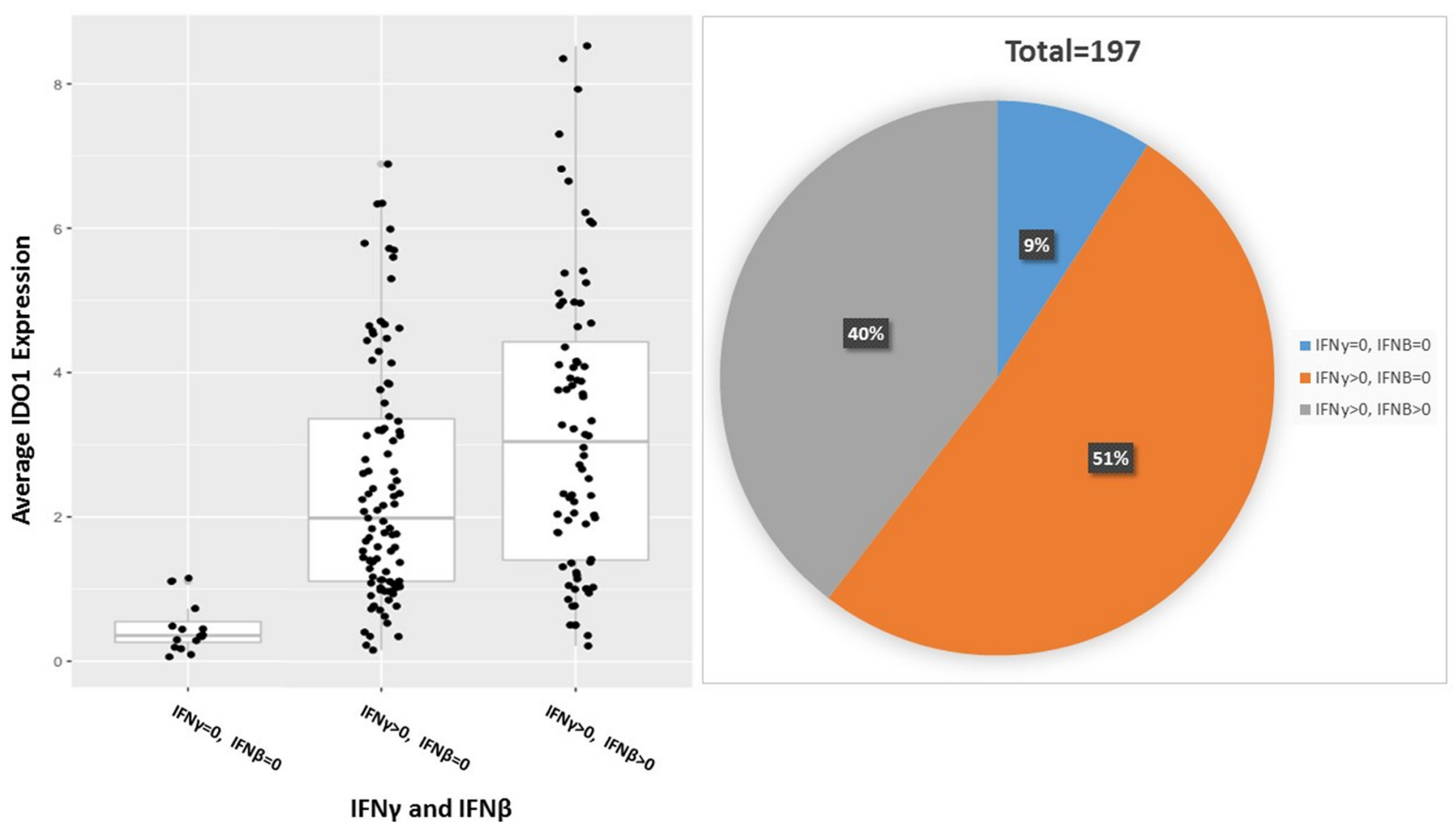

Figure 5: IFN-gamma and IFN-beta induce IDO1 expression in esophageal cancer; $\boldsymbol{P}=\mathbf{2 . 2 e - 0 7 .} 197$ total patient samples were stratified by IFN $\gamma$ and IFN $\beta$ expression into 3 cohorts: IFN $\gamma=0$ and IFN $\beta=0, \operatorname{IFN} \gamma>0$ and IFN $\beta=0$, IFN $\gamma>0$ and $\operatorname{IFN} \beta>0$. The percent of patient samples in each cohort is represented in a pie chart above. 


\section{IDO1 expression in esophageal cancer is associated with IFNy and IFN $\beta$}

In many tissues, IDO1 expression is undetectable [34], but rapidly induced and made detectable by pro-inflammatory stimuli [35]. Previous work has demonstrated that interferon-gamma (IFNy) secreted in the tumor microenvironment increases IDO1 expression, similar to PD-L1 [29, 32]. Interferon levels (IFNy and IFN $\beta$ ) were correlated with IDO1 expression in the esophageal cancer patient samples from the TCGA $(n=198)$. Samples with undetectable IFNy and IFN $\beta$ $(\mathrm{IFN \gamma}=0, \operatorname{IFN} \beta=0)$ was compared with detectable IFNy $(\operatorname{IFN\gamma }>0)$ and IFN $\beta(\operatorname{IFN} \beta>0) .1$ sample had detectable IFN $\beta$ but not IFNy, which was not included in analysis. Detectable IFNy and IFN $\beta$ correlated with increased average IDO1 expression (Figure 5; $P=2.2 \mathrm{e}-07)$.

\section{IDO1 protein expression is correlated with PD- L1 and CD3 $\varepsilon$ in esophageal cancer}

To determine whether the mRNA expression data correlated with protein levels, expression by immunohistochemistry (IHC) for IDO1 was investigated among 93 surgically-resected esophageal SCC tumors evaluated in a tumor microarray (TMA). Tissue samples were stained for IDO1, PD-L1, and CD3 $\varepsilon$, followed by light microscopic immunoscoring analysis (Figure 6) on a scale of 0 to 3.44 of 93 samples (47.3\%) stained positively for IDO1 expression. IDO1 protein expression strongly correlated with both PD-L1 (Figure 7; $P=0.0001$ ), and $\mathrm{CD} 3 \varepsilon$ protein localization (Figure $8 ; P<0.0001$ ). The expression of PD-L1 also strongly correlated with CD3 $\varepsilon$ (Figure 9; $P \leq 0.0001$ ).

IDO1 and PD-L1 expression by IHC in the surgically resected cohort was assessed for correlation with patient survival. In contrast to analysis of the TCGA data which correlated high IDO1 and PD-L1 levels with worse patient outcomes, in our surgically resected cohort expression of IDO1, PD-L1, and CD3e by IHC did not correlate with OS.

\section{DISCUSSION}

This investigation began with an evaluation of the prognostic role of IDO1 as a predictor of patient survival in esophageal cancer. Using mRNA gene expression of TCGA data, it was shown that increased IDO1 mRNA expression is associated with worse patient outcomes in esophageal cancer, both in SCC and AC histologies. It was further demonstrated that high PD-L1 mRNA expression, alone and in combination with high IDO1 expression, is associated with a worse overall patient survival.

While increased IDO1 expression has been associated with worse patient outcomes in a number of human malignancies [36] including esophageal SCC $[37,38]$, other tumors such as renal cell carcinoma, hepatocellular carcinoma, and melanoma demonstrate a correlation between IDO1 expression and improved survival [39]. This variable suggests a differential immunosuppressive role of IDO1 across tumor types. Our data support a potential negative prognostic impact of increased IDO1 expression in both SCC and AC histologies. Furthermore, these data corroborate previous reports of worsened patient outcomes in esophageal cancer with over-expression of PD-L1 and PD-L2 [40]. Previous work has suggested an association between cancer, inflammation, and increased IDO1 expression within tumors [31, 41], suggesting that similar to PD-L1, intratumoral inflammation may lead to adaptive resistance as a mechanism of tumor immune evasion within the tumor microenvironment.

This analysis also identified a correlation between IDO1 expression and the presence of IFN $\beta$ and IFN $\gamma$. This, too, is consistent with previous reports that IDO1 expression increases in response to IFN $\gamma$ produced by $\mathrm{CD}^{+} \mathrm{T}$ cells within the tumor microenvironment in melanoma [32]. Taken together, these findings support the hypothesis that PD-(L)1 inhibition may lead to increased IFN $\gamma$ levels as mediated by $\mathrm{CD} 8^{+} \mathrm{T}$-cells within esophageal cancers. This in turn may increase IDO1 expression as an adaptive immunosuppressive mechanism, contributing to resistance of checkpoint blockade.

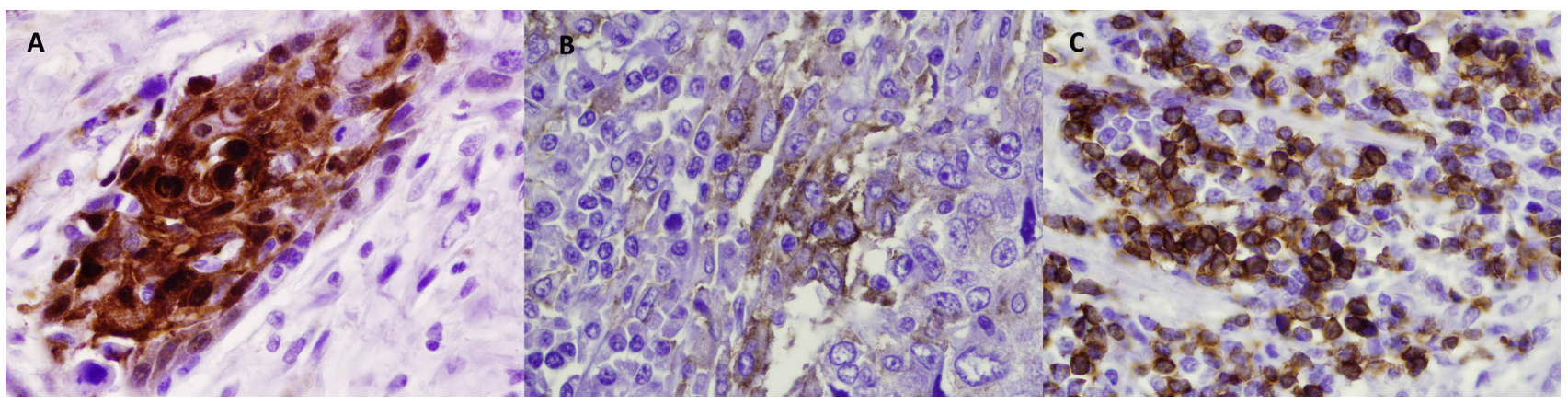

Figure 6: Representative IHC staining of resected esophageal SCC samples of IDO-1 (A), PD-L1 (B), and CD3ع (C). 
To further explore this hypothesis, an investigation of IDO1, PD-L1, and CD3e (T-cell marker) expression by IHC in an additional cohort of patients with surgically resected esophageal SCC was performed. Using correlative analysis, we found a strong association between IDO1, PD-L1, and CD $3 \varepsilon$ expression. This finding suggests that increased T-cell infiltration in the tumor microenvironment is associated with high expression of IDO1 and PD-L1 in esophageal cancer. This may occur through production of pro-inflammatory cytokines such as IFN $\gamma$ from T-cells within the tumor microenvironment. We hypothesize that the elevated IDO1 and PD-L1 expression in T-cell inflamed esophageal cancer lead to an immunosuppressive tumor microenvironment and contribute to worse OS. These findings suggest that IDO1 inhibition may be effective in a combinatorial approach with checkpoint inhibitor therapies in esophageal cancer. Of interest, checkpoint inhibition was recently combined

IDO1 and PD-L1 expression by IHC

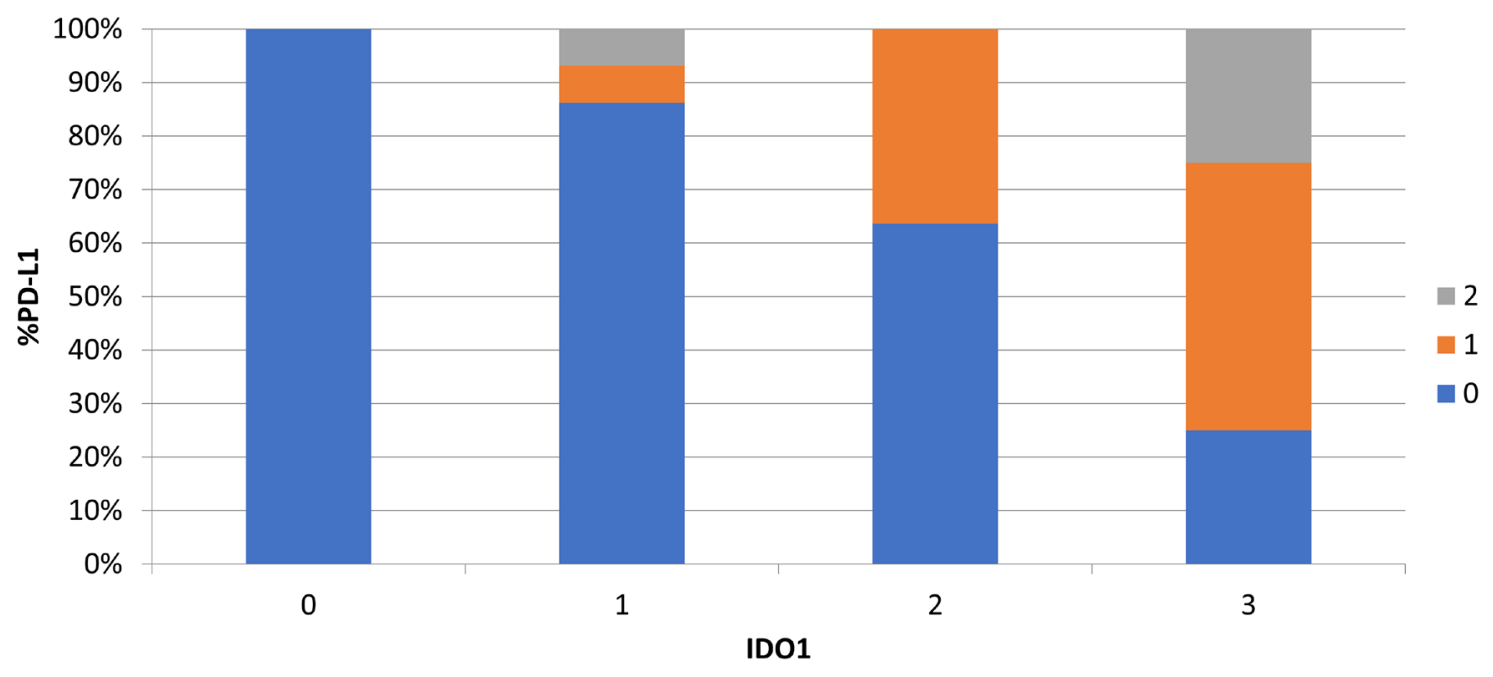

Figure 7: Increased IDO1 expression by IHC is correlated with increasing PD-L1 expression. 93 surgically resected esophageal SCC samples were stained by IHC for IDO1 expression and PD-L1 expression on a scale of 0 to 3 . Samples are shown graphically stratified by IDO1 expression demonstrating percent of PD-L1 expression on a scale of 0 to 3.

\section{IDO1 and CD3ع expression by IHC}

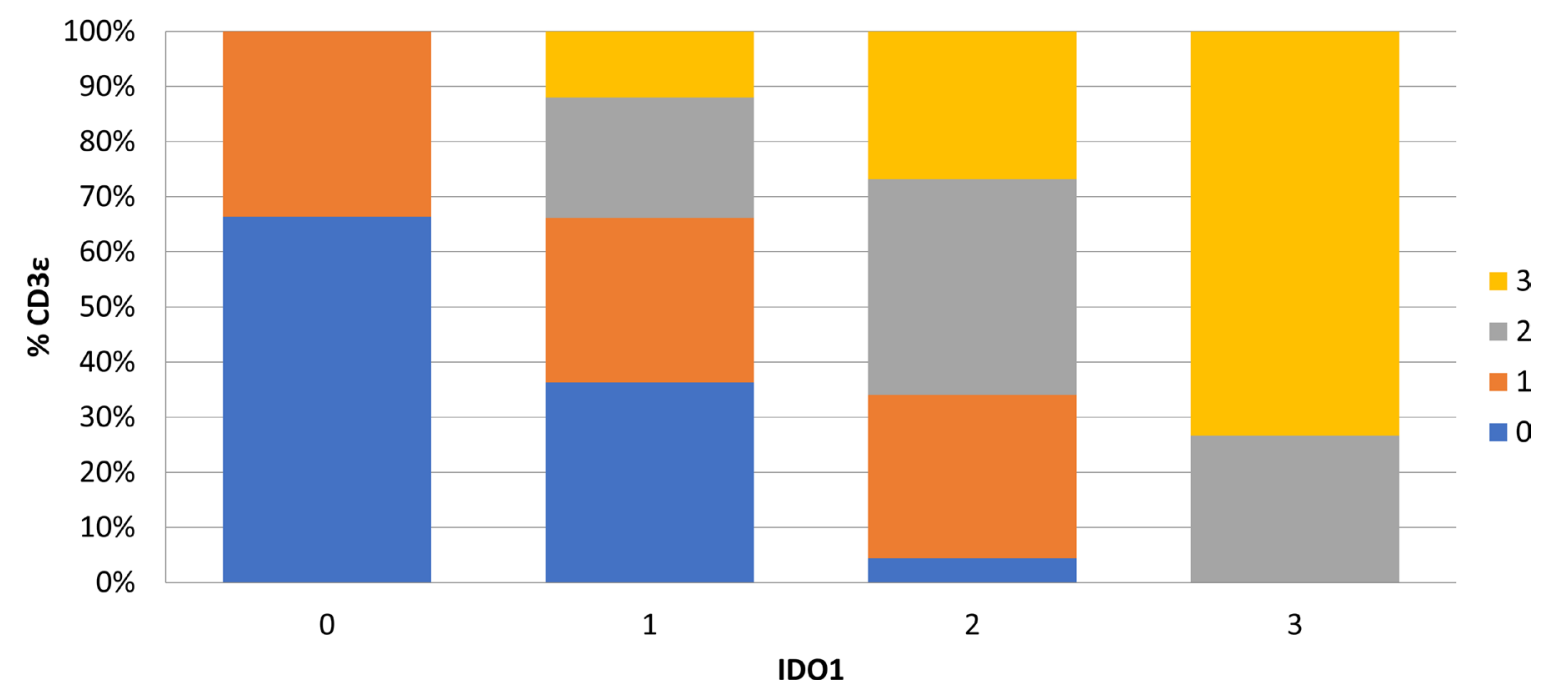

Figure 8: Increased IDO1 expression by IHC is correlated to increasing intratumoral CD3E expression. 93 surgically resected esophageal SCC samples were stained by IHC for IDO1 expression and CD3 $\varepsilon$ expression on a scale of 0 to 3 . Samples are shown graphically stratified by IDO1 expression demonstrating percent of CD $3 \varepsilon$ expression on a scale of 0 to 3 . 
with IDO1 inhibition in advanced melanoma which apparently improved response rates over single-agent PD-1 blockade [42]. This study's data suggests that similar to advanced melanoma, this may be an effective immunotherapeutic approach in esophageal cancer as well.

One limitation to this analysis is that CD $3 \varepsilon$ does not allow us to differentiate between $\mathrm{CD}^{+}$cytotoxic $\mathrm{T}$ cells (Tc), $\mathrm{CD}^{+} \mathrm{T}$-helper cells (Th), and $\mathrm{T}$ regulatory cells (Treg). Previous work suggests that tumor cell IDO1 facilitates Treg accumulation, and that Tc and Treg infiltrate IDO1 expressing tumors, which is associated with worse survival in animal models [43-45] Additional work evaluating IDO1 in esophageal cancer could include additional staining of tumor associated T-lymphocytes for CD8 (Tc) and FoxP3 (Treg) to further elucidate the T-cell composition within IDO1 over-expressing esophageal cancer. Also, the association of worse overall survival with IDO1 expression as determined by TCGA analysis was discordant with IDO1 expression by IHC in a second cohort, which did not find an association with overall survival. Variability in these methods has been previously reported [45]. This discrepancy could be further explored with an evaluation of in situ hybridization or NanoString for mRNA expression, along with IHC on the same tissue samples to demonstrate discordance between methods.

In conclusion, we hypothesize based on this correlative data that in esophageal cancer, use of combinatorial immune checkpoint blockade targeting IDO1 in combination with PD-(L)1 and CTLA-4 blockade may enhance the reactivation of tumor-infiltrating T-cells, decrease immunosuppressive Tregs, and therefore amplify T-cell mediated anti-tumor responses which may further improve patient outcomes with advanced esophageal cancer.

\section{MATERIALS AND METHODS}

\section{The cancer genome atlas (TCGA) sample description}

The TCGA data for all the cancer types analyzed in current study were accessed from the UCSC Xena browser (http://xena.ucsc.edu/). mRNA expression data represented by RNASeq (Illumina $\mathrm{Hi}$-seq platform) includes RSEM normalized level 3 data present in TCGA as of January 2017. DNA methylation data and exon expression RNASeq data were extracted from the same TCGA dataset. TCGA esophageal gene expression data by AffyU133a array were also acquired from the UCSC Xena browser.

\section{Immunohistochemistry (IHC) staining}

Esophageal squamous cell carcinoma human paraffin embedded tissue microarrays (US Biomax, Inc.) which were labeled "HEso-Squ172Sur-02." This consisted of 93 cases, 79 cases had tumor and matched normal adjacent tissue. Additional information available included clinical stage (I-III; AJCC 7th Ed.), survival information, surgery date (ranging from January 2009 through January 2010), with 3-4 year follow-up. The slides were incubated in decloaking chamber (Biocare Medical) at $110^{\circ} \mathrm{C}$ for 5 minutes; rinsed in distilled water 2 times and in $1 \times$ phosphate buffered saline (PBS) for 5 minutes, then incubated with anti-IDO1 antibody (clone: Cell Signaling antibody, \#86630, clone D5J4E), anti-PD-L1 antibody (clone: Abcam, ab205921, clone 28-8) (1:50 dilution), and anti-CD3e (clone: Abcam, ab16669, clone SP7) (1:50 dilution) in antibody diluent

\section{PD-L1 and CD3ع expression by IHC}

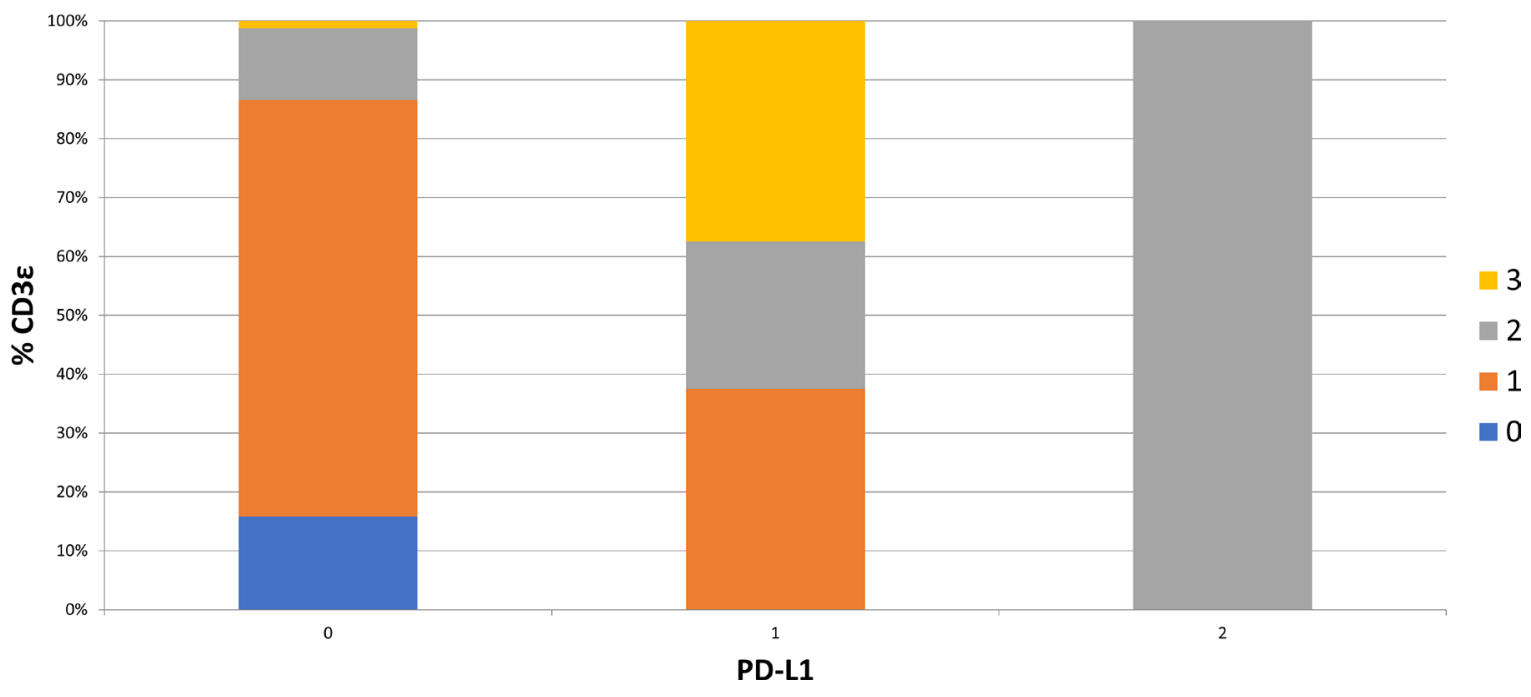

Figure 9: Increased PD-L1 expression by IHC is correlated to increasing intratumoral CD3E expression. 93 surgically resected esophageal SCC samples were stained by IHC for PD-L1 expression and CD3 $\varepsilon$ expression on a scale of 0 to 3 . Samples are shown graphically stratified by PD-L1 expression demonstrating percent of CD3e expression on a scale of 0 to 3 . 
(DAKO, Cat\# S0809) overnight at $4^{\circ} \mathrm{C}$. After rinsing with Tris-Buffered $\mathrm{NaCl}$ Solution with $0.1 \%$ Tween 20 (TBST) (DAKO), sections were further incubated with HRP-labelled anti-rabbit secondary antibody (DAKO, Cat\# K4011) for 30 minutes. Slides were then washed for 3 minutes. Immunohistochemical reactions were visualized using EnVision System-HRP (DAKO). Tissue sections were counterstained with hematoxylin Gill II (Surgipath), mounted in the mounting medium, and visualized under a light microscope. Quantitative IHC immunoscoring was subsequently performed by Victoria Villaflor, MD at Northwestern University.

\section{Statistical analysis}

The cutoff value for each gene expression level was determined with Cutoff Finder software (http:// molpath.charite.de/cutoff/) using significance as the cutoff optimization method [25]. Kaplan-Meier (KM) survival analysis was performed to estimate the survival distribution, while the log-rank test was used to assess the statistical significance of differences between the stratified survival groups using GraphPad Prism (version 6, GraphPad Software, Inc., La Jolla, CA). To assess statistical differences between stratified survival groups for coexpression curves, the log-rank test for trend was used. To assess correlation of IFN $\gamma$ and IFN $\beta$ with IDO1 levels, Kendall's rank correlation tau was used. Differences were considered to be statistically significant when $P<0.05$. IHC staining of IDO1, PD-L1, and CD3 $\varepsilon$ of esophageal SCC samples were correlated by Fisher's exact test. Differences were considered statistically significant when $P<0.05$.

\section{Abbreviations}

IDO1: (Indoleamine 2,3-dioxygenase 1); TCGA: (the cancer genome atlas); IHC: (immunohistochemistry); SCC: (squamous cell carcinoma); AC: (adenocarcinoma); PDL1: (programmed death ligand-1); GEJ: (gastroesophageal junction); CTLA-4: (cytotoxic T lymphocyte antigen-4); MSI-high (microsatellite instability - high); PFS: (progression free survival); OS (overall survival); GCN2: (general control non-depressible 2).

\section{Author contributions}

Ari Rosenberg, MD, John Hayes, MD, David D. Odell, MD, Srinadh Komanduri, MD, and Mary Mulcahy, MD were involved in writing the manuscript. Derek A. Wainwright, PhD, Matthew Genet, Lijie Zhai, PhD, Kristen L. Lauing, PhD, and Craig Horbinski, MD were involved in data collection, analysis, and laboratory techniques. Carlos Galvez, MD assisted with data collection. Alfred Rademaker, $\mathrm{PhD}$ and Kwang-Youn
Kim, PhD were involved in statistical analysis. Victoria M. Villaflor, MD was involved in oversight of the project.

\section{ACKNOWLEDGMENTS}

Thank you to Andrew Madrigal, MD, PhD who assisted in providing high-quality photographs of IHC of esophageal tissue specimens.

\section{CONFLICTS OF INTEREST}

There are no conflicts of interest relevant to the publication of this manuscript.

\section{FUNDING}

Funding for this project was obtained from the Daniel M. Hoyne Foundation and the Dixon Translational Research Grant, Northwestern University.

\section{REFERENCES}

1. Pohl H, Sirovich B, Welch HG. Esophageal adenocarcinoma incidence: are we reaching the peak? Cancer Epidemiol Biomarkers Prev. 2010; 19:1468-70. https:/doi. org/10.1158/1055-9965.EPI-10-0012.

2. Network NCC. Esophageal and Esophagogastric Junction Cancers.

3. Ramos-Suzarte M, Lorenzo-Luaces P, Lazo NG, Perez ML, Soriano JL, Gonzalez CE, Hernadez IM, Albuerne YÁ, Moreno BP, Alvarez ES, Callejo IP, Alert J, Martell JA, et al. Treatment of malignant, non-resectable, epithelial origin esophageal tumours with the humanized antiepidermal growth factor antibody nimotuzumab combined with radiation therapy and chemotherapy. Cancer Biology \& Therapy. 2012; 13:600-5. https://doi.org/10.4161/ cbt.19849.

4. Liang J, E M, Wu G, Zhao L, Li X, Xiu X, Li N, Chen B, Hui Z, Lv J, Fang H, Tang Y, Bi N, et al. Nimotuzumab combined with radiotherapy for esophageal cancer: preliminary study of a Phase II clinical trial. OncoTargets and Therapy. 2013; 6:1589-96. https://doi.org/10.2147/ OTT.S50945.

5. Iveson $\mathrm{T}$, Donehower RC, Davidenko I, Tjulandin S, Deptala A, Harrison M, Nirni S, Lakshmaiah K, Thomas A, Jiang Y, Zhu M, Tang R, Anderson A, et al. Rilotumumab in combination with epirubicin, cisplatin, and capecitabine as first-line treatment for gastric or oesophagogastric junction adenocarcinoma: an open-label, dose de-escalation phase $1 \mathrm{~b}$ study and a double-blind, randomised phase 2 study. Lancet Oncol. 2014; 15:1007-18. https://doi.org/10.1016/ S1470-2045(14)70023-3. 
6. Bang YJ, Van Cutsem E, Feyereislova A, Chung HC, Shen L, Sawaki A, Lordick F, Ohtsu A, Omuro Y, Satoh T, Aprile G, Kulikov E, Hill J, et al. Trastuzumab in combination with chemotherapy versus chemotherapy alone for treatment of HER2-positive advanced gastric or gastro-oesophageal junction cancer (ToGA): a phase 3, open-label, randomised controlled trial. The Lancet. 2010; 376:687-97. https://doi. org/10.1016/S0140-6736(10)61121-X.

7. Fuchs CS, Tomasek J, Yong CJ, Dumitru F, Passalacqua R, Goswami C, Safran H, dos Santos LV, Aprile G, Ferry DR, Melichar B, Tehfe M, Topuzov E, et al. Ramucirumab monotherapy for previously treated advanced gastric or gastro-oesophageal junction adenocarcinoma (REGARD): an international, randomised, multicentre, placebocontrolled, phase 3 trial. The Lancet. 2014; 383:31-9. https://doi.org/10.1016/S0140-6736(13)61719-5.

8. Wilke H, Muro K, Van Cutsem E, Oh SC, Bodoky G, Shimada Y, Hironaka S, Sugimoto N, Lipatov O, Kim TY, Cunningham D, Rougier P, Komatsu Y, et al. Ramucirumab plus paclitaxel versus placebo plus paclitaxel in patients with previously treated advanced gastric or gastro-oesophageal junction adenocarcinoma (RAINBOW): a double-blind, randomised phase 3 trial. Lancet Oncol. 2014; 15:1224-35. https://doi.org/10.1016/ S1470-2045(14)70420-6.

9. Schumacher TN, Schreiber RD. Neoantigens in cancer immunotherapy. Science. 2015; 348:69-74. https://doi. org/10.1126/science.aaa4971.

10. Robert C, Long GV, Brady B, Dutriaux C, Maio M, Mortier L, Hassel JC, Rutkowski P, McNeil C, Kalinka-Warzocha E, Savage KJ, Hernberg MM, Lebbe C, et al. Nivolumab in previously untreated melanoma without BRAF mutation. N Engl J Med. 2015; 372:320-30. https://doi.org/10.1056/ NEJMoa1412082.

11. Robert C, Schachter J, Long GV, Arance A, Grob JJ, Mortier L, Daud A, Carlino MS, McNeil C, Lotem M, Larkin J, Lorigan P, Neyns B, et al. Pembrolizumab versus Ipilimumab in Advanced Melanoma. N Engl J Med. 2015; 372:2521-32. https://doi.org/10.1056/NEJMoa1503093.

12. Borghaei H, Paz-Ares L, Horn L, Spigel DR, Steins M, Ready NE, Chow LQ, Vokes EE, Felip E, Holgado E, Barlesi F, Kohlhaufl M, Arrieta O, et al. Nivolumab versus Docetaxel in Advanced Nonsquamous Non-Small-Cell Lung Cancer. N Engl J Med. 2015; 373:1627-39. https:// doi.org/10.1056/NEJMoa1507643.

13. Sharma P, Retz M, Siefker-Radtke A, Baron A, Necchi A, Bedke J, Plimack ER, Vaena D, Grimm MO, Bracarda S, Arranz JA, Pal S, Ohyama C, et al. Nivolumab in metastatic urothelial carcinoma after platinum therapy (CheckMate 275): a multicentre, single-arm, phase 2 trial. Lancet Oncol. 2017; 18:312-22. https://doi.org/10.1016/ S1470-2045(17)30065-7.

14. Motzer RJ, Escudier B, McDermott DF, George S, Hammers HJ, Srinivas S, Tykodi SS, Sosman JA, Procopio
G, Plimack ER, Castellano D, Choueiri TK, Gurney H, et al. Nivolumab versus Everolimus in Advanced Renal-Cell Carcinoma. N Engl J Med. 2015; 373:1803-13. https://doi. org/10.1056/NEJMoa1510665.

15. Ferris RL, Blumenschein G Jr, Fayette J, Guigay J, Colevas AD, Licitra L, Harrington K, Kasper S, Vokes EE, Even C, Worden F, Saba NF, Iglesias Docampo LC, et al. Nivolumab for Recurrent Squamous-Cell Carcinoma of the Head and Neck. N Engl J Med. 2016; 375:1856-67. https://doi. org/10.1056/NEJMoa1602252.

16. Crocenzi TS, El-Khoueiry AB, Yau TC, Melero I, Sangro B, Kudo M, Hsu C, Trojan J, Kim TY, Choo SP, Meyer T, Kang YK, Yeo W, et al. Nivolumab (nivo) in sorafenib (sor)naiv e and -experienced pts with advanced hepatocellular carcinoma (HCC): CheckMate 040 study. Journal of Clinical Oncology. 2017; 35:4013. https://doi.org/10.1200/ JCO.2017.35.15_suppl.4013.

17. Kaufman HL, Russell J, Hamid O, Bhatia S, Terheyden P, D'Angelo SP, Shih KC, Lebbé C, Linette GP, Milella M, Brownell I, Lewis KD, Lorch JH, et al. Avelumab in patients with chemotherapy-refractory metastatic Merkel cell carcinoma: a multicentre, single-group, open-label, phase 2 trial. Lancet Oncol. 2016; 17:1374-85. https://doi. org/10.1016/S1470-2045(16)30364-3.

18. Ansell SM, Lesokhin AM, Borrello I, Halwani A, Scott EC, Gutierrez M, Schuster SJ, Millenson MM, Cattry D, Freeman GJ, Rodig SJ, Chapuy B, Ligon AH, et al. PD-1 blockade with nivolumab in relapsed or refractory Hodgkin's lymphoma. N Engl J Med. 2015; 372:311-9. https://doi.org/10.1056/NEJMoa1411087.

19. Fuchs CS, Doi T, Jang RWJ, Muro K, Satoh T, Machado M, Sun W, Jalal SI, Shah MA, Metges JP, Garrido M, Golan T, Mandala M, et al. KEYNOTE-059 cohort 1: Efficacy and safety of pembrolizumab (pembro) monotherapy in patients with previously treated advanced gastric cancer. Journal of Clinical Oncology. 2017; 35:4003. https://doi.org/10.1200/ JCO.2017.35.15_suppl.4003.

20. Le DT, Durham JN, Smith KN, Wang H, Bartlett BR, Aulakh LK, Lu S, Kemberling H, Wilt C, Luber BS, Wong F, Azad NS, Rucki AA, et al. Mismatch-repair deficiency predicts response of solid tumors to PD-1 blockade. Science. 2017; 357:409-13. https://doi.org/10.1126/science. aan6733.

21. Wolchok JD, Kluger H, Callahan MK, Postow MA, Rizvi NA, Lesokhin AM, Segal NH, Ariyan CE, Gordon RA, Reed K, Burke MM, Caldwell A, Kronenberg SA, et al. Nivolumab plus ipilimumab in advanced melanoma. $\mathrm{N}$ Engl J Med. 2013; 369:122-33. https://doi.org/10.1056/ NEJMoa1302369.

22. Postow MA, Chesney J, Pavlick AC, Robert C, Grossmann K, McDermott D, Linette GP, Meyer N, Giguere JK, Agarwala SS, Shaheen M, Ernstoff MS, Minor D, et al. Nivolumab and Ipilimumab versus Ipilimumab in Untreated 
Melanoma. N Engl J Med. 2015; 372:2006-17. https://doi. org/10.1056/NEJMoa1414428.

23. Janjigian YY, Ott PA, Calvo E, Kim JW, Ascierto PA, Sharma P, Peltola KJ, Jaeger D, Jeffry Evans TR, De Braud FG, Chau I, Tschaika M, Harbison CT, et al. Nivolumab \pm ipilimumab in pts with advanced (adv)/metastatic chemotherapy-refractory (CTx-R) gastric $(\mathrm{G})$, esophageal (E), or gastroesophageal junction (GEJ) cancer: CheckMate 032 study. Journal of Clinical Oncology. 2017; 35:4014. https://doi.org/10.1200/JCO.2017.35.15_suppl.4014.

24. Kang YK, Satoh T, Ryu MH, Chao Y, Kato K, Chung HC, Chen JS, Muro K, Kang WK, Yoshikawa T, Oh SC, Tamura T, Lee KW, et al. Nivolumab (ONO-4538/BMS-936558) as salvage treatment after second or later-line chemotherapy for advanced gastric or gastro-esophageal junction cancer (AGC): A double-blinded, randomized, phase III trial. Journal of Clinical Oncology. 2017; 35:2. https://doi. org/10.1200/JCO.2017.35.4_suppl.2.

25. Muro K, Chung HC, Shankaran V, Geva R, Catenacci D, Gupta S, Eder JP, Golan T, Le DT, Burtness B, McRee AJ, Lin CC, Pathiraja K, et al. Pembrolizumab for patients with PD-L1-positive advanced gastric cancer (KEYNOTE-012): a multicentre, open-label, phase $1 \mathrm{~b}$ trial. Lancet Oncol. 2016; 17:717-26. https://doi.org/10.1016/ S1470-2045(16)00175-3.

26. Doi T, Piha-Paul SA, Jalal SI, Mai-Dang H, Saraf S, Koshiji M, Csiki I, Bennouna J. Updated results for the advanced esophageal c arcinoma cohort of the phase $1 \mathrm{~b}$ KEYNOTE-028 study of pembrolizumab. Journal of Clinical Oncology. 2016; 34:4046. https://doi.org/10.1200/ JCO.2016.34.15_suppl.4046.

27. Li F, Zhang R, Li S, Liu J. IDO1: An important immunotherapy target in cancer treatment. Int Immunopharmacol. 2017; 47:70-7. https://doi.org/10.1016/j. intimp.2017.03.024.

28. Stone TW, Darlington LG. Endogenous kynurenines as targets for drug discovery and development. Nat Rev Drug Discov. 2002; 1:609-20. https://doi.org/10.1038/nrd870.

29. Zhai L, Spranger S, Binder DC, Gritsina G, Lauing KL, Giles FJ, Wainwright DA. Molecular Pathways: Targeting IDO1 and Other Tryptophan Dioxygenases for Cancer Immunotherapy. Clin Cancer Res. 2015; 21:5427-33. https://doi.org/10.1158/1078-0432.CCR-15-0420.

30. Metz R, Rust S, Duhadaway JB, Mautino MR, Munn DH, Vahanian NN, Link CJ, Prendergast GC. IDO inhibits a tryptophan sufficiency signal that stimulates mTOR: A novel IDO effector pathway targeted by D-1-methyltryptophan. Oncoimmunology. 2012; 1:1460-8. https://doi. org/10.4161/onci.21716.

31. Muller AJ, DuHadaway JB, Chang MY, Ramalingam A, Sutanto-Ward E, Boulden J, Soler AP, Mandik-Nayak L, Gilmour SK, Prendergast GC. Non-hematopoietic expression of IDO is integrally required for inflammatory tumor promotion. Cancer Immunol Immunother. 2010; 59:1655-63. https://doi.org/10.1007/s00262-010-0891-4.
32. Spranger S, Spaapen RM, Zha Y, Williams J, Meng Y, Ha TT, Gajewski TF. Up-regulation of PD-L1, IDO, and $\mathrm{T}$ (regs) in the melanoma tumor microenvironment is driven by CD8(+) T cells. Sci Transl Med. 2013; 5:200ra116. https://doi.org/10.1126/scitranslmed.3006504.

33. Tumeh PC, Harview CL, Yearley JH, Shintaku IP, Taylor EJ, Robert L, Chmielowski B, Spasic M, Henry G, Ciobanu V, West AN, Carmona M, Kivork C, et al. PD-1 blockade induces responses by inhibiting adaptive immune resistance. Nature. 2014; 515:568-71. https://doi.org/10.1038/ nature 13954.

34. Theate I, van Baren N, Pilotte L, Moulin P, Larrieu P, Renauld JC, Herve C, Gutierrez-Roelens I, Marbaix E, Sempoux C, Van den Eynde BJ. Extensive profiling of the expression of the indoleamine 2,3-dioxygenase 1 protein in normal and tumoral human tissues. Cancer Immunol Res. 2015; 3:161-72. https://doi.org/10.1158/2326-6066. CIR-14-0137.

35. Carlin JM, Borden EC, Sondel PM, Byrne GI. Biologicresponse-modifier-induced indoleamine 2,3-dioxygenase activity in human peripheral blood mononuclear cell cultures. J Immunol. 1987; 139:2414-8.

36. Brochez L, Chevolet I, Kruse V. The rationale of indoleamine 2,3-dioxygenase inhibition for cancer therapy. Eur J Cancer. 2017; 76:167-82. https://doi.org/10.1016/j. ejca.2017.01.011.

37. Jia Y, Wang H, Wang Y, Wang T, Wang M, Ma M, Duan Y, Meng X, Liu L. Low expression of Bin1, along with high expression of IDO in tumor tissue and draining lymph nodes, are predictors of poor prognosis for esophageal squamous cell cancer patients. Int J Cancer. 2015; 137:1095-106. https://doi.org/10.1002/ijc.29481.

38. Zhang G, Liu WL, Zhang L, Wang JY, Kuang MH, Liu $\mathrm{P}$, Lin YH, Dai SQ, Du J. Involvement of indoleamine 2,3-dioxygenase in impairing tumor-infiltrating CD8 T-cell functions in esophageal squamous cell carcinoma. Clin Dev Immunol. 2011; 2011:384726. https://doi. org/10.1155/2011/384726.

39. Zhai L, Ladomersky E, Lenzen A, Nguyen B, Patel R, Lauing KL, Wu M, Wainwright DA. IDO1 in cancer: a Gemini of immune checkpoints. Cellular And Molecular Immunology. 2018 Jan 29. https://doi.org/10.1038/cmi.2017.143. [Epub ahead of print].

40. Ohigashi Y, Sho M, Yamada Y, Tsurui Y, Hamada K, Ikeda N, Mizuno T, Yoriki R, Kashizuka H, Yane K, Tsushima F, Otsuki N, Yagita H, et al. Clinical significance of programmed death-1 ligand-1 and programmed death-1 ligand-2 expression in human esophageal cancer. Clin Cancer Res. 2005; 11:2947-53. https://doi. org/10.1158/1078-0432.CCR-04-1469.

41. Muller AJ, Sharma MD, Chandler PR, Duhadaway JB, Everhart ME, Johnson BA 3rd, Kahler DJ, Pihkala J, Soler AP, Munn DH, Prendergast GC, Mellor AL. Chronic inflammation that facilitates tumor progression creates local immune suppression by inducing indoleamine 2,3 
dioxygenase. Proc Natl Acad Sci U S A. 2008; 105:17073-8. https://doi.org/10.1073/pnas.0806173105.

42. Zakharia Y, McWilliams R, Shaheen M, Grossman K, Drabick J, Milhem M, Rixie O, Khleif S, Lott R, Kennedy E, Munn D, Vahanian N, Link C. Abstract CT117: Interim analysis of the Phase 2 clinical trial of the IDO pathway inhibitor indoximod in combination with pembrolizumab for patients with advanced melanoma. Cancer Research. 2017; 77:CT117-CT. https://doi.org/10.1158/1538-7445. am2017-ct117.

43. Wainwright DA, Balyasnikova IV, Chang AL, Ahmed AU, Moon KS, Auffinger B, Tobias AL, Han Y, Lesniak MS. IDO Expression in Brain Tumors Increases the Recruitment of Regulatory T Cells and Negatively Impacts Survival. Clinical Cancer Research. 2012; 18:6110-21. https://doi. org/10.1158/1078-0432.ccr-12-2130.
44. Zhai L, Ladomersky E, Dostal CR, Lauing KL, Swoap K, Billingham LK, Gritsina $\mathrm{G}, \mathrm{Wu} \mathrm{M}$, McCusker RH, Binder DC, Wainwright DA. Non-tumor cell IDO1 predominantly contributes to enzyme activity and response to CTLA-4/PD-L1 inhibition in mouse glioblastoma. Brain Behav Immun. 2017; 62:24-9. https://doi.org/10.1016/j. bbi.2017.01.022.

45. Zhai L, Ladomersky E, Lauing KL, Wu M, Genet M, Gritsina G, Gyorffy B, Brastianos PK, Binder DC, Sosman JA, Giles FJ, James CD, Horbinski C, et al. Infiltrating $\mathrm{T}$ Cells Increase IDO1 Expression in Glioblastoma and Contribute to Decreased Patient Survival. Clin Cancer Res. 2017; 23:6650-6660. https:// doi.org/10.1158/1078-0432.CCR-17-0120. 